\title{
O microempreendedor individual como política pública brasileira de exclusão da desigualdade social
}

\author{
The individual micro entrepreneur as a brazilian public policy \\ exclusion from social inequality
}

Helton Carlos Praia de Lima ${ }^{1}$

Wastony Aguiar Bittencourt ${ }^{2}$

\begin{abstract}
RESUMO
A Lei Complementar brasileira $n^{\circ} 128$ de dezembro de 2008 criou uma figura jurídica, cuja denominação é Microempreendedor Individual (MEI), com objetivo de trazer para a formalidade todos os negócios que viviam à margem das instituições fiscalizatórias das três esferas de poder: municipal, estadual e federal. Ao retirar da informalidade milhões de trabalhadores autônomos, desempregados e empreendedores natos, surge a possibilitar de inserção do grupo no cenário socioeconômico brasileiro formal. Nesse sentido, o objetivo da pesquisa foi analisar se o MEI se beneficiou da política pública brasileira de exclusão da desigualdade social por intermédio desse instrumento legal. Para tanto, a metodologia utilizada foi a do método dedutivo; quantos aos meios a pesquisa foi a bibliográfica e documental e quanto aos fins foi qualitativa, com base nos dados da Receita Federal e do Sebrae. O resultado foi de que a política pública utilizada para o Microempreendedor Individual tem alcançado sucesso, embora, necessite de ajustes.
\end{abstract}

PALAVRAS-CHAVE:

Política pública; Desigualdade social; Microempreendedor Individual.

\begin{abstract}
1 Professor de Direito da Graduação e Pós-Graduação do CIESA. Doutor em Direito Constitucional pela Universidade de Fortaleza (UNIFOR, 2019). Mestre em Contabilidade e Controladoria pela Universidade Federal do Amazonas (UFAM, 2014). Pós-graduado em Direito do Trabalho e Previdenciário pelo Centro Universitário de Ensino Superior do Amazonas (CIESA, 2002). Graduado em Direito (CIESA,2001). Graduado em Ciências Contábeis (CIESA, 1993). Graduado em Tecnologia Eletrônica pela Universidade do Estado do Amazonas (UTAM / UEA, 1984) e graduado em Licenciatura em Física (UFAM, 1985). Foi Professor de Direito da Universidade Paulista - UNIP/Manaus. Auditor-Fiscal da Receita Federal do Brasil (aposentado). Foi Conselheiro do Conselho Administrativo de Recursos Fiscais (CARF) e Presidente da 3 Turma Especial da 2 Seção de Julgamento, do Ministério da Economia. Advogado. Área de atuação: Direito Constitucional, Tributário, Trabalho e Previdenciário, Julgamento, Processos Tributários, Contabilidade e Controladoria.

2 Doutorando em Direito Constitucional (DINTER UNIFOR/CIESA).Possui graduação em Tecnólogo em Manutenção Mecânica pelo Instituto de Tecnologia da Amazônia (1992), graduação em Direito com ênfase em Direito Financeiro e Tributário pela Faculdade Martha Falcão (2009), graduação em Engenharia Industrial Mecânica pelo Instituto de Tecnologia da Amazônia (2004) e mestrado em Engenharia de Produção pela Universidade Federal do Amazonas (2002). Auditor-Fiscal de Tributos Municipais.
\end{abstract}


The Brazilian Complementary Law $n^{\circ} 128$ of December 2008 created a legal figure, whose name is Individual Microentrepreneur (MEI), with the objective of bringing to formality all the businesses that lived outside the inspection institutions of the three spheres of power: municipal, state and federal. By removing millions of self-employed, unemployed and born entrepreneurs from informality, it is possible to include the group in the formal Brazilian socioeconomic scenario. In this sense, the objective of the research was to analyze whether the MEI benefited from the Brazilian public policy for the exclusion of social inequality through this legal instrument. For that, the methodology used was the deductive method; how much to the means the research was the bibliographic and documentary and how much to the ends it was qualitative, based on the data of the Federal Revenue and Sebrae. The result was that the public policy used for the Individual Microentrepreneur has been successful, although it needs adjustments.

KEYWORDS:

Public policy. Social inequality. Individual Microentrepreneur.

\section{INTRODUÇÃO}

A Constituição Federal determina, como princípio da ordem econômica, que seja dispensado, pelos entes públicos, tratamento favorecido às pequenas empresas que, é disciplinado pela Lei Complementar $\mathrm{n}^{\circ} 123$ de 14 de dezembro de 2006, que vem a ser o Estatuto Nacional das Microempresas e Empresas de Pequeno Porte. O referido diploma contempla medidas mitigadoras de deveres nos mais variados campos obrigacionais, como na legislação trabalhista, na previdenciária e na seara do direito administrativo. Essas medidas, na sua maioria, são de índole especificamente tributária e alcançam os entes federais, estaduais e municipais. A base de sua existência é a simplificação, redução e até eliminação de obrigações tributárias principais e acessórias da União, dos Estados, do Distrito Federal e dos Municípios para formar um sistema tributário especial chamado "Simples Nacional".

Em 2008, por intermédio da Lei Complementar 128 de 19 de dezembro de 2008, criouse uma outra figura jurídica, cuja denominação é Microempreendedor Individual (MEI), como objetivo específico era trazer para a formalidade todos aqueles negócios que viviam a margem das instituições fiscalizatórias, nas três esferas, municipal, estadual e federal. Um dos objetivos foi o de requalificar o pequeno empresário para Microempreendedor Individual (MEI) e fixar 
tratamento diferenciado com expedientes ainda mais simplificados e favoráveis que os dispensados para as microempresas e empresas de pequeno porte.

O MEI tem como principal atrativo o pagamento simplificado de valores mensais e de pequeno valor comparado a tributação normal exigida das empresas, a facilidade de constituição do negócio formal, bem como, a facilidade de encerramento da atividade (baixa de inscrições) nas três esferas de fiscalização. Além disso, tem outras facilidades tais como, o não pagamento da taxa de verificação de funcionamento regular, mais conhecida como alvará, e a facilidade de o sistema estar todo ele informatizado, gerando velocidade para pagamento dos valores devidos, entre outros.

Dessa forma, em razão das facilidades, que foram colocadas, para que os empreendedores pudessem se formalizar, cresceu de maneira rápida a quantidade de pessoas que migraram para este tipo de tributação, com praticidade e velocidade. Assim, várias pessoas que viviam na informalidade resolveram se tornar novos empresários, e com isso, regularizando a sua situação em diversas frentes tributárias e empresárias, sendo detentor de direitos e deveres, deixando uma vida de incertezas, para gerar renda e oportunidades.

Nesse sentido, diante da possibilidade legal de formalização gerada ao Microempreendedor Individual, tem-se como objetivo analisar se o MEI se beneficiou da política pública brasileira de exclusão da desigualdade social, e como objetivos específicos: relacionar as questões do MEI como alternativa para geração de renda, e estudar o cenário nacional brasileiro no viés das políticas públicas e exclusão social.

A metodologia utilizada foi a do método dedutivo, partindo-se de uma contextualização mundial, para o particular de seus princípios legais quanto às questões de políticas públicas e a exclusão social, afim de verificar o alcance do MEI como um instrumento mitigador das desigualdades sociais; quantos aos meios a pesquisa foi a bibliográfica e documental e quanto aos fins foi qualitativa, com fontes de dados da Receita Federal e do Serviço de apoio às micro e pequenas empresas (SEBRAE).

O artigo está organizado em quatro partes, primeiramente, uma introdução sobre o assunto. Na segunda parte se tem a contextualização do Microempreendedor Individual (MEI) no cenário brasileiro. $\mathrm{Na}$ terceira parte faz-se uma abordagem sobre as políticas públicas 
referentes ao Microempreendedor Individual (MEI), utilizando dados da Receita Federal e do Sebrae, em seguida as considerações finais e por último as referências.

\section{CONTEXTUALIZAÇÃO DO MICROEMPREENDEDOR INDIVIDUAL (MEI) CENÁRIO BRASILEIRO}

A Constituição brasileira de 1988 estabeleceu que para a estruturação de um Estado democrático de direito a República Federativa do Brasil deve buscar construir uma sociedade livre, justa e solidária, garantir o desenvolvimento nacional, erradicar a pobreza e a marginalização, bem como reduzir as desigualdades sociais e regionais, garantindo o bem de todos. Pautando como fundamentos do Estado Brasileiro entre outros, a dignidade da pessoa humana e valores sociais do trabalho e da livre iniciativa (POMPEU e SIQUEIRA, 2017).

De acordo com Pompeu e Siqueira (2017) esses fundamentos e objetivos alicerçam a ordem econômica que, fundada na valorização do trabalho humano e na livre iniciativa, tem por fim assegurar a todos existência digna, conforme os ditames da justiça social, com respaldo na soberania nacional, na propriedade privada, na função social da propriedade, na livre concorrência, na defesa do consumidor, na defesa do meio ambiente e na redução das desigualdades regionais e sociais.

Dessa forma, ao se destacar que a ordem econômica está alicerçada em dois pontos importantes, a livre iniciativa e a valorização do trabalho, onde uma está diretamente ligada a outra o que se busca é garantir a chamada dignidade humana, para se alcançar a justiça social (MEIRA JUNIOR; MACEI, 2017)

Concebido inicialmente como uma disciplina jurídica instrumental, o direito financeiro, ao longo do século XX, assumiu uma íntima conexão com o direito econômico, abandonado a pretensa neutralidade do período anterior. Nesta perspectiva, a evolução do direito financeiro refletiu o protagonismo do Estado na organização do capitalismo no segundo pós-guerra, denotando a integração progressiva entre a economia e as finanças públicas e legitimando a participação ativa do Estado no domínio econômico. O direito financeiro afirmou-se como um 
dos campos mais controvertidos da ciência jurídica, incorporando as tensões e as contradições da relação entre o poder do Estado e a sociedade na organização capitalista (BERCOVICI e MASSONETO, 2006, p. 4).

Essa participação do Estado, nada mais é do que aquele Estado que ao participar da economia acaba por tornar-se sócio de todas as atividades econômicas gerando uma dependência por parte daqueles que, ou não querem ou não aprenderam a desenvolver atividades de cunho econômico para desenvolvimento próprio. Acabando por estimular o gigantismo na participação do Estado.

De acordo com Nunes (2003, p. 115), a exclusão social é um dos fenômenos mais dramáticos do nosso tempo. E um fenômeno qualitativamente novo: quando se falava de exploradores e explorados, havia que contar com estes, porque os explorados estavam dentro do sistema (sem explorados não pode haver exploradores), enquanto os excluídos estão, por definição, fora do sistema, como se não existissem.

À luz desta realidade, é difícil não concordar com aqueles autores (Celso Furtado é um deles) que sustentam que os problemas reais do desenvolvimento dos países subdesenvolvidos são mais de natureza política do que econômica. E a verdade é que vários documentos da ONU consagram o direito ao desenvolvimento como um direito fundamental dos povos. Basta recordar o Pacto Internacional de Direitos Econômicos, Sociais e Culturais (16 de Dezembro de 1996), a declaração sobre o Progresso e o Desenvolvimento no Domínio Social (11 de Dezembro de 1996), a Declaração sobre o Direito ao Desenvolvimento (aprovada pela assembleia geral da ONU em 1986) e o Programa de Ação aprovado em Viena em 1993, na Conferência das Nações Unidas sobre Direitos Humanos, no qual se proclama que o direito ao desenvolvimento é um direito universal e inalienável e uma parte integrante dos direitos humanos fundamentais (NUNES, 2003, p. 115).

A participação do Estado não é só desenvolvendo políticas que sustentem a população, criando uma dependência que na medida em que mais e mais pessoas desejam usufruir desses mecanismos, mais recursos são necessários para que se possa manter esse tipo de tratamento. Se defende, sim, um Estado que ao mesmo tempo que desenvolva políticas de desenvolvimento da população, também privilegie o desenvolvimento de mais empresas e de mais empreendedores para gerar uma economia forte e saudável. 
Em relação à Desenvolvimento Nunes (2003, p. 116) destaca que, em primeiro lugar, a ideia de que o desenvolvimento econômico passa por caminhos que respeitem a dignidade do homem, o desenvolvimento integral da sua personalidade, a conquista do bem-estar material, mas também o desenvolvimento dos homens, no plano da sua profissão, da cultura e do lazer.

Em segundo lugar, a ideia de que o desenvolvimento é condicionado por determinada estruturas e implica, portanto, transformações mais ou menos profundas dessas estruturas (a estrutura da propriedade, a estrutura das relações de produção, as estruturas sociais, a própria estrutura do poder político).

Em terceiro lugar, a ideia de que sem ignorar a necessidade do crescimento econômico enquanto crescimento do Produto Nacional Bruto (PNB) o desenvolvimento deve colocar-se, fundamentalmente, ao serviço da satisfação das necessidades básicas das populações (alimentação, saúde, educação de base, serviços de água e saneamento, transportes e habitação). O conceito de necessidades básicas implica a satisfação de necessidades imediatas, mas também de necessidades cuja satisfação é, nos dias de hoje, um pressuposto indispensável para que as pessoas possam efetivamente atingir níveis razoáveis de produtividade e desenvolver atividades produtivas suficientemente remuneradoras, o que significa a acentuação do caráter social destas necessidades.

O conceito de necessidades básicas tende hoje a incluir-se também a ideia de que o desenvolvimento implica o direito a um grau razoável de igualdade entre os cidadãos do mesmo país, no que toca designadamente à repartição do rendimento e ao acesso às condições básicas de desenvolvimento e de promoção social (NUNES,203 p. 117).

Estamos novamente a verificar a importância dos aspectos políticos na definição de uma estratégia aceitável de desenvolvimento, escrevem Irma Adelman e Cynthia Morris, "é o desenvolvimento do povo, pelo povo e para o povo. Sem novas instituições e políticas especificamente orientadas para melhorar a sorte dos pobres não há alternativa realista de justiça social no mundo subdesenvolvido do nosso tempo" (NUNES, 2003 p. 118).

Na medida em que as "regras do jogo" de sobrevivência e vida na terra estão mudando, surge a necessidade de novos referenciais para o estabelecimento das relações sociais, dentro de outra perspectiva de desenvolvimento, que vem se mostrando como emergente desafiando o 
modo de pensar e agir de pessoas e organizações, principalmente por considerar a existência de diferentes níveis de realidade e por defender que o ser humano é parte integrante da natureza, contestando a perspectiva de dominação e superioridade do ser humano (BIER e AMORIM, 2013, p. 40) .

As discussões sobre essas duas possibilidades (manutenção e ajuste do status quo ou mudança real e significativa de paradigma) permeiam todo arcabouço teórico ora proposto, considerando a mudança paradigmática possível e necessária, posicionando nesse contexto, as discussões sobre o papel e reais influências do sistema econômico, onde o mercado deve ser visto como apenas mais uma das dimensões de qualquer projeto de sociedade (BIER e AMORIM, 2013, p. 41).

As políticas públicas voltadas para os microempreendedores não nasceram com o MEI - microempreendedor individual, em 2008. Elas remontam a 1945, por intermédio do DecretoLei $\mathrm{n}^{\circ} 7.661$, de 21 de junho de 1945, onde os empreendedores, estavam dispensados da apresentação de certos documentos em caso de concordata e a exclusão de punição. Dessa forma, em se comprovando a hipossuficiência, dos comerciantes individuais e do pequeno comerciante, os mesmos estavam dispensados da apresentação de tais documentos. (SCHOURI; GALDINO, pag. 295)

\section{POLÍTICAS PÚBLICAS E O MICROEMPREENDEDOR INDIVIDUAL (MEI)}

O neoliberalismo é o paradigma econômico e político que define o nosso tempo. Ele consiste em um conjunto de políticas e processos que permitem a um número relativamente pequeno de interesses particulares controlar a maior parte possível da vida social com o objetivo de maximizar seus benefícios individuais. Inicialmente associado a Reagan e Thatcher, o neoliberalismo é a principal tendência da política e da economia globais nas últimas duas décadas, seguida, além da direita, por partidos políticos de centro e por boa parte da esquerda tradicional. Esses partidos e suas políticas representam os interesses imediatos de investidores extremamente ricos e de menos de mil grandes empresas (CHOMSKY, 2002, p. 3). 
As consequências econômicas dessas políticas têm sido as mesmas em todos os lugares e são exatamente as que se poderia esperar: um enorme crescimento da desigualdade econômica e social, um aumento marcante da pobreza absoluta entre as nações e povos mais atrasados do mundo, um meio ambiente global catastrófico, uma economia global instável e uma bonança sem precedente para os ricos. Diante desses fatos, os defensores da ordem neoliberal nos garantem que a prosperidade chegará inevitavelmente até as camadas mais amplas da população - desde que ninguém se interponha à política neoliberal que exacerba todos esses problemas. (CHOMSKY, 2002, p. 3).

Percebe-se que regulamentações públicas e sociais mais solidárias e sustentáveis devem ser engendradas, capazes de resolver as questões mundiais relativas aos mercados e aos fatores de produção. Gerar emprego e renda, por meio da atração de novas empresas, faz parte da agenda prioritária dos Estados, assim como o combate à corrupção e ao desvio de recursos públicos, a busca de transparência e celeridade judicial. Essa missão, que se dá por meio das regulamentações que melhoram a atividade de negócios, necessita do cumprimento dos princípios da administração pública: legalidade, impessoalidade, moralidade, publicidade e eficiência. Devem se fazer presentes em todas as funções do Estado (legislativa, executiva e judiciária) (POMPEU e SIQUEIRA, 2002, p. 192).

Essa agenda deve ser prioritária para todos os Estados. O esforço deve ser repartido com a população. Deve-se permanentemente melhorar todos os níveis de transparência, assim como, o ambiente empreendedor, facilitando e melhorando as formas de pagar tributos e pensando não em formas de aumentar essa tributação, e sim, melhorar a forma de tributar ampliando a base de contribuintes com isso aumentando significativamente as arrecadações.

O conceito de democracia como concepção equitativa entre pessoas livres e iguais, segundo Pompeu e Siqueira (2017, p. 213), Rawls fundamenta os seus dois modelos de princípios de justiça: igualdade de liberdades básicas, justas oportunidades e princípio da desigualdade. Ou seja; a democracia pressupõe que as pessoas mereçam igual consideração do Estado, isto é, que sejam reconhecidas igualmente dignas em suas individualidades, de maneira que o governo não deve preferir, prioritariamente e arbitrariamente, determinados modelos de vida em detrimento de outros. Mas para que se vivencie a equidade como ausência de hierarquias, é necessário que se assegure a justa oportunidade e que se realize o princípio da 
diferença, indispensável à justificativa das desigualdades sócio econômicas em uma sociedade entre iguais.

De acordo com Pompeu e Siqueira (2017, p. 234), a conclusão não poderia ser outra: a construção coerente e parcimoniosa do direito é condição indispensável para a realização dos direitos humanos pelas cortes constitucionais, em tal momento da prática jurídica, deve-se preservar a seriedade e responsabilidade do direito. Os anseios judiciais, justificáveis, ressaltase, de realização da dignidade humana deve dar-se sob os imperativos metodológicos da coerência e sob os limites materiais da equidade.

A simples disposição de oferecer crédito aos pobres já era um passo revolucionário para o pensamento econômico convencional. Significou ignorar a convicção tradicional de que não se pode conceder empréstimos sem garantia de pagamento. Essa suposição conservada pela grande maioria dos banqueiros, sem nem ao menos analisar, questionar ou refletir a respeito, classificando metade dos seres humanos como indigno de participar do sistema financeiro (MUHAMMED, 2008, p. 66).

De acordo com o autor, visto de maneira mais ampla, o sistema do Banco Grameen também envolve a reconsideração de muitas outras suposições vigentes na economia convencional. $\mathrm{O}$ autor chegou a discutir o fato de que a teoria econômica esboça uma imagem radicalmente simplificada da natureza humana, assumindo que todas as pessoas são motivadas apenas pelo desejo de maximizar lucros. Bastam somente alguns segundos de reflexão sobre as pessoas que se conhece no contexto real para perceber que tal suposição é incorreta. E esse foi apenas um dos pontos cegos da teoria econômica convencional que o Banco Grameen teve de superar.

Um outro ponto é a ideia de que a solução para a pobreza está na criação de empregos para todos, e que o único modo de ajudar os pobres é dando-lhes trabalho. Tal suposição configura os tipos de política de desenvolvimento que os economistas recomendam e que os governos e agências de ajuda humanitária buscam. O dinheiro das doações é revestido em projetos gigantescos, a maioria gerenciada pelo governo. O capital privado é investido em grandes empreendimentos que supostamente impulsionam as economias locais e regionais enquanto empregam milhares de pessoas e transformam pobres em contribuintes abastados. É 
uma boa teoria, mas a experiência mostra que isso não funciona porque não existem as condições de apoio necessárias (MUHAMMED, 2008, p. 66).

Nesse aspecto se torna necessário que as políticas também sejam voltadas para o empreender das pessoas, oportunizando para as mesmas formas de se tornarem donas de seu próprio negócio. E não só, fazendo com que esse ambiente de negócios possa contagiar a população de maneira significativa dando cada vez mais oportunidades para que a economia possa crescer dando o retorno necessário para um ambiente negocial sadio.

O direito ao desenvolvimento foi positivado, expressamente, na Declaração das Nações Unidas de 1986, que lhe deu contornos normativos, no âmbito internacional, e passou a ser reconhecido como direito humano. Pelo referido documento, os Estados assumiram o dever e o direito - de - formular políticas nacionais adequadas para o desenvolvimentoll, visando ao bem-estar da população, por meio, inclusive, de sua participação nesse processo (art. $2^{\circ}$, III). O desenvolvimento humano, portanto, transformou-se em norma para a conduta dos Estados, tanto nacional quanto internacionalmente (art. $3^{\circ}$ ) (FORTES e POMPEU, 2016 p. 57).

Como se percebe, o princípio que orientaria fundamentalmente as relações na sociedade internacional, para uma cultura de paz, seria aquele baseado na ideia de solidariedade enquanto único caminho para o desenvolvimento humanitário, ou seja, a cooperação dos povos para o progresso da humanidade, como ficou inscrito no art. 4, IX, da Constituição de 1988.

De acordo com Fortes e Pompeu (2016, p. 58), em outro sentido, isso parece interferir, também, no processo político-democrático, uma vez que, por serem tais compromissos assumidos externamente, de alguma forma, vinculam - potencialmente - a ação dos governos nacionais, influindo, por um lado, nas decisões estratégicas, e, por outro, retirando o foco e alguma energia das questões que entram no debate político. Além disso, também a democracia é alvo de motivação e normatização internacional, vista até como pressuposto para a meta do desenvolvimento humano, a Declaração sobre o Direito ao Desenvolvimento (DDD/86) anuncia que "a pessoa humana é o sujeito central do desenvolvimento e deveria ser participante ativo e beneficiário do direito ao desenvolvimento" (art. $\left.2^{\circ}, \mathrm{I}\right)$.

Todas as instituições e (a maioria dos) indivíduos deveriam prestar atenção aos problemas dos desfavorecidos em cada nação e em cada região. Observamos que a soberania 
nacional, apesar de moralmente importante, arrisca isolar da crítica e da mudança a situação das mulheres e de outros grupos em desvantagem em cada nação. A situação das pessoas cuja qualidade de vida é especialmente baixa, medida pela lista das capacidades, deve consequentemente ser um foco persistente de atenção para a comunidade mundial como um todo, não apenas para as instituições, mas para todos os indivíduos que não estão normalmente eles próprios sobrecarregados (NUSSBAUM, 2013, p. 394).

A autora observa que, apesar de somente em alguns casos serem apropriados sanções coercivas, nossa habilidade em justificar um conjunto mais rico de normas deve conduzir a esforços incansáveis de persuasão e mobilização política, como o trabalho que levou à Convenção sobre a eliminação de Todas as Formas de Discriminação contra as Mulheres. O uso seletivo de financiamento pode ajudar enormemente o processo de aumentar o padrão de vida dessas pessoas e grupos.

O princípio da dignidade da pessoa humana é um dos fundamentos da organização nacional e passou a se constituir no vértice para o qual convergem todos os direitos individuais e coletivos proclamados nas constituições democráticas de uma sociedade cada vez mais pluralista. Por analogia, a dignidade da pessoa humana não pode ser aviltada pelo Estado com a imposição tributária que exceda à capacidade contributiva do contribuinte.

Por outro lado, o Estado tem o dever de instituir e cobrar tributos para poder fazer frente às despesas necessárias para a sua manutenção, e também custear as necessidades imediatas e mediatas da população. Quando se tributa observando-se os princípios gerais do Direito, promove -se a justiça social, porque somente deve contribuir quem tem capacidade contributiva, e na medida de sua capacidade de suportar o ônus tributário.

A matéria tributária é tratada nos títulos VI e VIII da Constituição Federal de 1988. Mesmo estando fora do capítulo I do título II não resta suprimido o caráter fundamental do dever de pagar tributos, vez que a organização econômica no Estado Democrático de Direito está a serviço da materialização do princípio da dignidade da pessoa humana.

Observa-se ainda que a sujeição ao tributo não implica em um dever em sentido estrito, mas sim uma sujeição constitucional decorrente do dever de solidariedade e dos poderes do Estado, além de estar abrangido também pelos princípios fundamentais da constituição 
econômica. Dá-se então a necessária relação entre a constituição econômica e a constituição do indivíduo, constituindo-se o jusfundamentalismo.

Direitos fundamentais, visto que criam os pressupostos básicos para uma vida na liberdade e na dignidade humana. Cuida-se, portanto, dos direitos inerentes à própria noção dos direitos básicos da pessoa, que constituem a base jurídica da vida humana no seu nível atual de dignidade. Portanto, não se trata apenas dos direitos estatuídos pelo legislador constituinte, mas também dos direitos resultantes da concepção de Constituição dominante, da ideia de Direito, do sentimento jurídico coletivo (OLIVEIRA, 2004). O autor ressalta ainda que no sistema jurídico brasileiro, essas ponderações ostentam enorme alcance prático, porque a Constituição de 1988 positivou de forma expressa os direitos fundamentais de primeira, segunda e terceira geração.

$\mathrm{Na}$ órbita da execução dos direitos fundamentais por meio das políticas públicas é que a Justiça Fiscal mostra sua força. Consubstanciada na receita e na despesa, compreende a arrecadação suficiente e aplicação eficiente do arrecadado, encontrando aí o seu maior problema: baixa contraprestação e alta incidência direta e indireta da tributação. Tal problemática no Brasil tem ares históricos ante a situação colonialista em que o Brasil vivia regando a Metrópole com seus produtos primários e sem ver qualquer contraprestação positiva. A situação exclusivamente exploratória e desmedida criou raízes com os novos habitantes portugueses cujo perfil era dos chamados degregados, ou punidos de banimento muitas vezes por crimes como a sonegação de impostos (CREDDO, 2012, p.195).

De acordo com estudos da Receita Federal (Receita Federal, 2018) aponta que a arrecadação tributária no Brasil cresce ano a ano, batendo novos recordes em arrecadação. Um outro estudo compara a voracidade tributária de 30 países com o nível de bem-estar dos cidadãos, medido pelo Índice de Desenvolvimento Humano (IDH), elaborado pelo IFI Instituto Fiscal Independente, do Senado Federal. E conclui: "Entre os 30 países com a maior carga tributária, o Brasil continua sendo o que proporciona o pior retorno dos valores arrecadados em prol do bem-estar da sociedade”. Embora, o gasto social, tenha sido em torno de pouco mais de $60 \%$ da carga tributária ou em torno de $20 \%$ do PIB, em comparação com os países da OCDE - Organização para Cooperação e Desenvolvimento Econômico, que é formada por 36 países, a carga e os gastos sociais são bem próximos, sendo que da OCDE giram em torno de $20 \%$ da carga tributária (IFI, 2018) 
O MEI - Microempreendedor individual, foi criado para tirar da informalidade todos aqueles negócios caracterizados como pequenos negócios. Assim, atividades como sapateiro, cuidador de idosos, manicure, cabeleireiro, entre outros estão dispostos na Lei Complementar 128/08, para que possam regularizar sua situação e ao mesmo tempo desenvolver na formalidade uma fonte de renda para seu sustento.

O regramento da Lei Complementar 128/08, veio alterar a Lei Complementar 123/06, e uma das possibilidades para que o MEI, possa usufruir e poder optar por um pagamento fixo mensal, independente dos valores auferidos como receita bruta e dentro da margem legal. Assim, e de acordo com os artigos 18-A, 18-B e 18-C, da LC 123/06, esses valores devem ser pagos ao Munícipio, se for prestador de serviços, ao Estado, se fizer a circulação de mercadorias e à União. Sendo que os valores para cada ente são $\mathrm{R} \$ 5,00$ (cinco reais) para o município, $\mathrm{R} \$$ 1,00 (um real) para o Estado e 5\% do salário mínimo para a União, para fins de contribuição da previdência. (SANTOS, 2019, p. 205).

São inúmeras as vantagens em ser Microempreendedor Individual, entre elas está a possibilidade de poder usufruir da nota fiscal de serviço, pagar um percentual de $5 \%$ a título de contribuição para a seguridade social, isenção do Imposto sobre operações financeiras (IOF), isenção do imposto sobre importação de produtos estrangeiros (II), isenção do imposto sobre a exportação para o exterior de produtos nacionais ou nacionalizados (IE), isenção do imposto sobre e propriedade territorial rural (ITR), do imposto de renda (IR) relativos aos rendimentos ou ganhos líquidos auferidos em aplicações de renda fixa ou variável e também dos ganhos de capital auferidos na alienação de bens do ativo permanente. (SANTOS,2018, p. 209)

Vive-se em um mundo em que simplesmente não é verdade que cooperar com os outros em termos justos seja vantajoso para todos. Garantir a todos os seres humanos as oportunidades básicas, exigirá certamente sacrifícios dos indivíduos e das nações mais ricas. Dessa forma, a teoria do contrato social clássica, inclusive a sua versão moralizada kantiana, não é suficiente para estabelecer uma forma inclusiva de cooperação social que trate todos os seres humanos com igual respeito. Mas não se deve deixar que os defeitos dessa concepção desanimem (NUSSBAUM, 2013, p. 337).

Que tipo de educação o modelo antigo de desenvolvimento preconiza? A educação voltada para o crescimento econômico exige competências básicas, que a pessoa seja 
alfabetizada e tenha noções básicas de aritmética. Também necessita que algumas pessoas possuam conhecimentos mais avançados de informática e tecnologia. A igualdade de acesso, porém, não é extremamente importante; um país pode muito bem crescer enquanto os camponeses pobres continuam analfabetos e sem dispor dos recursos básicos de informática, como demonstram os acontecimentos recentes em muitos estados indianos. Em estados como Gujarat e andhra Pradesh, assistimos ao aumento do PIB per capita por meio da educação de uma elite técnica, o que torna o estado atraente para os investidores externos (NUSSBAUM, 2015 p. 20).

A autora observa ainda que, os resultados desse crescimento não se refletiram na melhoria da saúde e das condições de vida dos camponeses pobres, e não existe nenhum motivo para pensar que o crescimento econômico exija que eles recebam uma educação adequada. Esse foi sempre o principal e mais importante problema do paradigma de desenvolvimento baseado no PIB per capita. Ele não dá importância à distribuição, e pode avaliar positivamente países ou estados em que os níveis de desigualdade são alarmantes. É o que ocorre com a educação: dada a natureza da economia da informação, os países podem aumentar o PIB sem se preocupar muito com o acesso à educação, desde que criem uma elite tecnológica e empresarial competente.

O modelo de Desenvolvimento Humano está comprometido com a democracia, uma vez que poder opinar na escolha das políticas que governam sua própria vida é um ingrediente essencial de uma vida merecedora de dignidade humana. No entanto, o tipo de democracia que ele favorece será o que atribui um papel importante a direitos fundamentais que não possam ser retirados das pessoas por meio dos caprichos da maioria - assim, ele favorecerá uma firme proteção da liberdade política; a liberdade de palavra, de associação e de prática religiosa; e direitos fundamentais em outras áreas como educação e saúde. Esse modelo combina bem com as aspirações da Constituição indiana (e pela da África do Sul) (NUSSBAUM, 2013, p.25).

Ainda de acordo com a autora, os Estados Unidos nunca deram proteção constitucional, ao menos em nível federal, a direitos nas áreas "sociais e econômicas" como a da saúde e da educação; no entanto, os americanos também estão convencidos de que a capacidade que todos os cidadãos possuem para alcançar esses direitos é um sintoma importante do êxito do país. Portanto, o Modelo de Desenvolvimento Humano não significa um falso idealismo; ele está 
estreitamente relacionado aos compromissos constitucionais, nem sempre plenamente cumpridos, de muitas (se não da maioria) das nações democráticas do mundo.

A aparente superação da vulnerabilidade financeira externa no início do novo milênio se deu no bojo de uma fase excepcionalmente positiva da economia internacional, com nova valorização cambial, aumento dos preços das commodities exportadas e a acumulação de reservas internacionais em volumes inéditos na história econômica do país. Os governos de Lula pretendiam realizar um projeto de "inserção soberana" na globalização, com a retomada do velho "social-desenvolvimentismo", impulsionado por uma nova agenda de ativismo estatal, processo acelerado sobretudo no governo de sua sucessora, que produziu erros estupendos de política econômica, ademais do aprofundamento de uma corrupção que alcançou níveis inéditos, com o quase desmantelamento da Petrobras. A chamada "Nova Matriz Econômica", baseada na redução política dos juros, no aumento exagerado do crédito para fins de consumo e na adoção de políticas setoriais de qualidade sofrível (quando não tisnadas pela corrupção), foi um fracasso completo, como se revelou a partir de 2015, produzindo a maior recessão de toda a história econômica do Brasil. O país está agora condenado a enfrentar um longo e penoso processo de ajuste nos anos à frente, sem que, no entanto, se vislumbre a retomada de uma fase de crescimento mais vigoroso (ALMEIDA, 2017, p. 19).

$\mathrm{O}$ autor ressalta que, por características estruturais próprias - modesta propensão à poupança, existência de um Estado intervencionista e "despoupador líquido", um contrato social-constitucional exageradamente distributivista, uma baixíssima (talvez até piorando) qualidade da educação, o que se reflete em crescimento medíocre da produtividade -, o Brasil é um país perfeitamente preparado para não crescer, ou apenas fazê-lo a taxas extremamente modestas, o que prenuncia um futuro bastante negativo em termos de acumulação de riqueza para quando terminar seu atual bônus demográfico. Trata-se de um país que deveria, necessariamente, empreender várias reformas radicais em suas estruturas econômicas e instituições políticas, mas dotado de elites dirigentes, atuantes ou potenciais, excepcionalmente medíocres e totalmente despreparadas para enfrentar esse tipo de desafio.

Independentemente das inevitáveis dificuldades políticas ligadas a uma nova (mas eventual) fase de reformas ousadas, registre-se que o atraso atual do Brasil, comparativamente a outros emergentes de renda média, não se deve tanto a fatores materiais ou técnicos, mas sim a essa mediocridade mental de suas elites - todas elas, de sindicalistas mafiosos a capitalistas 
corruptos e banqueiros promíscuos, em especial líderes políticos e religiosos alienados -, o que promete ancorar o Brasil num atraso quase permanente, ou pelo menos incontornável no futuro previsível (ALMEIDA, 2017, p. 19).

De acordo com Santos (2016) a figura do Microempreendedor Individual (MEI) se caracteriza como um estímulo para que o pequeno empreendedor se mantenha regular perante a legislação tributária. Essa "nova figura de contribuinte" foi criada pela Lei Complementar 128/2008, que incluiu dispositivos à Lei Complementar 123/2006.

A Lei Complementar $\mathrm{n}^{\circ}$ 147/14 contemplou ao microempreendedor individual (MEI) com várias medidas específicas de fomento. Com uma redação mais clara e abrangente que a anterior, o $\S 3^{\circ}$, art. $4^{\circ}$ da Lei Complementar $n^{\circ} 123 / 06$, eliminou os custos, inclusive prévios, relativos à abertura, à inscrição, ao registro, ao funcionamento, ao alvará, à licença, ao cadastro, às alterações e procedimentos de baixa e encerramento e aos demais itens relativos ao Microempreendedor Individual, incluindo os valores referentes a taxas, a emolumentos e a demais contribuições relativas aos órgãos de registro, de licenciamento, sindicais, de regulamentação, de anotação de responsabilidade técnica, de vistoria e de fiscalização do exercício de profissões regulamentadas.

Ademais, os conselhos representativos das categorias econômicas foram proibidos de exigir qualquer obrigação, além daquelas previstas na lei complementar, para a inscrição do MEI nos seus quadros (art. 18-A, § 19). Por meio da introdução do art. 18-D na Lei Complementar $\mathrm{n}^{\circ}$ 123/06, os Municípios se tornaram obrigados, quanto ao IPTU, a assegurar "tratamento mais favorecido ao MEI para realização de sua atividade no mesmo local em que residir, mediante aplicação da menor alíquota vigente para aquela localidade, seja residencial ou comercial, nos termos da lei, sem prejuízo de eventual isenção ou imunidade existente", regra peculiar por ser relativa a tributo até então não disciplinado no Estatuto.

Outra novidade inventiva, por se tratar de um estímulo indireto ao MEI, foi implementada pela nova redação do $\S 1^{\circ}$, art. 18-B da Lei Complementar $n^{\circ} 123 / 06$. Ao revés de o MEI ser agraciado com mitigações das suas próprias obrigações, os destinatários diretos das medidas foram os seus contratantes, pois deixaram de ser obrigados a preencher a Guia de Recolhimento do FGTS e de Informações à Previdência Social (GFIP) e a recolher a CPP, o que representa uma significativa redução dos custos de contratação. 
A exoneração, contudo, não se aplica quando o MEI contratado preste serviços de hidráulica, eletricidade, pintura, alvenaria, carpintaria e de manutenção ou reparo de veículos (§ $1^{\circ}$, art. 18-B, da LC 123/06). Também não é aplicada quando estiverem presentes os elementos da relação de emprego ( $\S 2^{\circ}$, art. 18-B, da LC 123/06), ou seja, pessoalidade, subordinação e habitualidade. Nesse caso, o contratante permanece sujeito a todas as obrigações decorrentes dessa relação, inclusive trabalhistas, tributárias e previdenciárias, tal medida busca evitar o fenômeno denominado por "pejotização", que consiste em encobrir uma relação de emprego por meio da inscrição do empregado como pessoa jurídica. Afinal, o objetivo do tratamento jurídico favorecido é beneficiar os empreendimentos miúdos e não enfraquecer as relações trabalhistas.

O novo diploma reduziu sanções pecuniárias pelo descumprimento de obrigações acessórias, quando estabelecidas em valor fixo ou por meio de patamar mínimo. A atenuação foi fixada em 90\% para os MEI e 50\% para os demais MPE, sem prejuízo da aplicação de valores específicos mais favoráveis, quando existentes. Ressalta-se, contudo, que tais reduções só são aplicáveis para o pagamento da multa no prazo de até 30 dias após a sua notificação e não abarcam as situações de fraude, resistência e embaraço à fiscalização.

Uma das alterações na Lei Complementar nº 123/2006, foi a inclusão da obrigatoriedade de aplicação dos benefícios às Micro e Pequenas Empresas nas contratações públicas. O artigo 47 da Lei Complementar $n^{\circ} 123 / 2006$, alterado pela Lei Complementar $n^{\circ} 147 / 2014$, esboça dois mandamentos de magnitude constitucional: o tratamento favorecido às MPEs e o desenvolvimento da economia local e regional, concebendo, portanto, o raciocínio nuclear que impera em todas as aquisições públicas.

O Brasil hoje tem mais de 11 milhões de microempresários que optaram pelo regime tributário Simples Nacional, depois de dez anos do sistema em vigor, de acordo com o sitio da Receita Federal. (RECEITA FEDERAL, 2020). E de acordo, com a pesquisa SEBRAE, pesquisa quantitativa, feita em junho de 2019, e contou com a participação de 10.339 entrevistas, feitas por telefone, em todo o Brasil, com perguntas fechadas e implementadas no período de 01/04 a 28/05/2019, 76\% de todos os entrevistados tinham apenas uma fonte de renda e essa fonte de renda era ser Microempreendedor Individual (MEI). 
Dessa forma, e se levando em consideração que existe um grande número de desempregados, se constata que a política pública, de inclusão MEI, dá oportunidade para que essas pessoas possam se formalizar e assim ter um rendimento. Com também é possível, ter um empregado, esse tipo de empreendimento também, ajuda a diminuir a quantidade de pessoas não empregadas.

Em matéria realizada por Sérgio Rodas (2014) são assinaladas algumas análises tributárias realizadas em relação ao Simples Nacional, onde destaca-se que, as empresas aptas à tributação pelo Simples Nacional já podem desde novembro agendar a adesão ao sistema, com a novidade que neste ano as empresas de serviços também podem aderir ao modelo tributário que promete simplificar e reduzir os tributos. Contudo, o que se tem observado é que para essas empresas a opção não vem sendo vantajosa.

De acordo com análises tributárias que se tem feito, em média, apenas para 20\% das empresas é positiva a opção pelo Simples. Para as demais, "essa opção representará em aumento da carga tributária, apesar da simplificação dos trabalhos”, explica Monica Maria dos Santos, consultora tributária da Confirp Consultoria Contábil, que conta que mais de cem análises tributárias já foram feitas.

Ocorre que a regulamentação do Governo estabeleceu alíquotas muito altas para a maioria das empresas de serviços, sendo que foi criada uma nova faixa de tributação, o Anexo VI, na qual "a carga a ser recolhida tem início em 16,93\% do faturamento, indo até 22,45\%. Com esses percentuais assustadores, a adesão pode levar ao aumento da carga tributária", alerta a consultora da Confirp.

O Anexo VI engloba empresas dos seguintes ramos de atividade: jornalismo e publicidade, medicina, inclusive laboratorial e enfermagem, medicina veterinária, odontologia, psicologia, psicanálise, terapia ocupacional, acupuntura, podologia, fonoaudiologia, despachantes, arquitetura, engenharia, pesquisa, design, desenho e agronomia, representação comercial, perícia, leilão e avaliação, auditoria, economia, consultoria, gestão, organização, controle e administração, e outras atividades do setor de serviços que tenham por finalidade a prestação de serviços decorrentes do exercício de atividade intelectual que não estejam nos Anexos III, IV ou V. 
Assim, a recomendação da Confirp para as empresas desses setores é de buscar o mais rápido possível por uma análise tributária. "Se a carga tributária for menor ou até mesmo igual, com certeza será muito vantajosa a opção pelo Simples, pelas facilidades que proporcionará para essas empresas", finaliza Monica Maria dos Santos.

Com a Lei Complementar n. 123/2006 reviu-se toda a regulamentação da Lei n. 9.317/1996, introduzindo novos parâmetros e comandos.

\begin{abstract}
Art. 751. Preceitos legais - Esse tratamento fiscal diferenciado deve-se ao princípio previsto no art. 170, IX, e ao preceituado no art. 179 da CF/1988. Postado no Capítulo I - Dos princípios gerais da atividade econômica, sob o Título VII - Da Ordem Econômica e Financeira, o dispositivo em tela reza: "A União, os Estados, o Distrito Federal e os Municípios dispensarão às microempresas e às empresas de pequeno porte, assim definidas em lei, tratamento jurídico diferenciado, visando a incentiválas pela simplificação de suas obrigações administrativas, tributárias, previdenciárias e creditícias, ou pela eliminação ou redução destas por meio de lei".
\end{abstract}

Tendências econômicas que conduzem a economia em posição de equilíbrio, possibilitam determinações de preços e quantidades de bens, descrevendo-as como uma adaptação aos dados atuais. Por outro lado, há distinção na produção de bens e serviços concorrendo para a manutenção de equilíbrio e resultados diferenciados. Essa dinâmica constitui um novo desenvolvimento baseado em desenvolvimento precedente, onde a produção de bens ocorre mediante novos arranjos e combinações de recursos. Neste sentido, o empreendedor gera a força motor que impulsiona mudanças fundamentais ao desenvolvimento (SCHUMPETER, 1988).

Com isso, os Microempreendedores Individuais dispõem do incentivo ao seu desenvolvimento por meio da simplificação das suas responsabilidades tributárias, favorecendo uma readequação e adaptação às novas demandas de mercado, considerando as necessidades regionais em cada contexto social, com o intuito de fortalecer o desenvolvimento regional.

O tema do desenvolvimento regional ou, dito ainda de outra maneira, da questão regional é um daqueles temas que encontram pouca ressonância nos assuntos da conjuntura econômica e política de uma nação. São, assim, problemas que se constituem, regra geral, no horizonte de longo prazo de uma nação ou região. Referem-se a questões estruturais a serem equacionadas, removidas ou superadas. Estão no campo da necessidade de se empreender uma mudança estrutural, uma reorientação de sentido e de trajetória nas vigas balizadoras do (sub)desenvolvimento regional. Esta perspectiva própria da compreensão do regional nos 
desafia, portanto, a refletir como cada passo dado numa determinada conjuntura adiciona ou subtrai passos necessários à árdua caminhada do longo prazo (NETO et al., 2017, p. 21).

O SEBRAE (Serviço Brasileiro de apoio às Micro e Pequenas empresas) principal incentivador das micro e pequenas empresas tem acompanhado via pesquisa o desenvolvimento dessa modalidade e um dado chama a atenção, na última pesquisa divulgada em maio de 2017, a modalidade MEI foi a opção de cerca de $50 \%$ das pessoas que estão com emprego (denominado na pesquisa como empregado (a) com carteira), e logo em seguida com o percentual de $22 \%$ vêm os que tem pequenos negócios - denominado na pesquisa como empreendedor informal e sem CNPJ).

A pesquisa abrangeu um universo de 10.328 entrevistas e teve como marcos iniciais e finais respectivamente (17/02 a 11/04/2017) e foi realizada em todo o Brasil. Em relação ao dado que chama a atenção é que essa modalidade foi criada para formalização do empreendedor informal, justamente o que aparece em segundo lugar, onde se conclui que existe um aproveitamento por parte de quem não era o alvo desse tipo de tributação. De onde se conclui que existe um enviesado, nesta proposta de tributação, uma vez que os negócios que estão sendo formalizados não são os informais, embora também estejam (SEBRAE, 2013).

Portanto, o que se percebe é que o MEI, esta modalidade de tributação está sendo compreendida como uma oportunidade de empreender por parte daqueles que trabalham como pessoas com carteira assinada e pensam ter uma renda extra como Microempreendedores individuais. Ora, faz parte da pesquisa também todas as outras faixas devidamente estratificadas, como sejam, os empreendedores informais, os desempregados e toda uma gama de possíveis empreendedores. É certo, que a pesquisa detectou que o percentual de pessoas que teoricamente deveriam ser atendidas por esta nova modalidade de tributação estava em terceiro lugar. Assim, compreende-se que a modalidade Empreendedor Individual também está atingindo a faixa de pessoas para quem estava direcionada, como seja, os empreendedores informais.

Ao se analisar também o regramento da política de inclusão social MEI, contida na Lei Complementar 123/2006, nos artigos 18-E, constata-se que seu objetivo é a inclusão social e previdenciária e não tem caráter físcal ou econômico. (BRASIL, 2020) 
Como política de inclusão é o Microempreendedor Individual uma excelente oportunidade para início de determinados tipos de negócios. É uma forma, de testar e até mesmo de verificar como está o mercado diante daquele tipo de empreendimento que foi adotado como sendo o inicial para determinada pessoa. Dessa forma, e levando em consideração que nem todos conseguem superar os problemas do dia a dia para realmente ter sucesso, a modalidade torna-se uma excelente escolha para começar um negócio. Mais, muitos têm sucesso, melhorando de maneira significativa uma boa parcela da economia.

\section{CONSIDERAÇÕES FINAIS}

Diante as observações realizadas no decorrer da pesquisa, percebe-se que, um dos principais desafios das políticas públicas vem ser o de criar condições necessárias e favoráveis ao aumento da produtividade dos Microempreendedores Individuais já formalizados a fim de propiciar o almejado desenvolvimento econômico e social.

Aponta-se o MEI como uma estratégia de superação do estado de pobreza. Pois, a entrada do MEI na atividade econômica tem sido um dos principais meios dos trabalhadores adquirirem seu sustento frente à queda do emprego formal no Brasil. Até o final de 2019, quase 10 milhões de pessoas já tinham se formalizado com MEI, por um lado diminuindo o desemprego por ter uma fonte de renda e por outro também oferecendo uma possibilidade de oferecer emprego. De onde, se conclui que ao sair da informalidade, gerou retorno para a previdência social (inclusão social), e para a sociedade de maneira geral em busca da chamada função social da empresa.

Existem problemas, que devem ser superados, como é o caso da utilização do MEI na chamada "pejotização", ou seja, no lugar de contratar um empregado o que se faz é contratar uma microempresa individual, mascarando uma situação que deveria ser de empregado e patrão.

Diversos autores, como POMPEU e SIQUEIRA e CREDDO, já escreveram sobre as condições que o Estado deve desenvolver por meio das políticas públicas para o 
desenvolvimento. Alguns defendem que o ser humano é empreendedor por natureza. Basta dar condições básicas suficientes que estas pessoas conseguem dar uma resposta significativa para a sociedade, como também, para a economia. Alguns defendem o Estado forte, intervencionista, outros defendem um Estado mais regulador.

Inúmeros são os programas que o Brasil possui com o objetivo de dar ao cidadão condições de um desenvolvimento sustentável. Com a criação do Microempreendedor Individual, em atenção à previsão constitucional, foi possível tirar da informalidade muitas daquelas pessoas que desenvolviam suas atividades sem qualquer proteção por parte do Estado.

A população se beneficiou com este importante instrumento de igualdade tributária, fazendo com que as pessoas pudessem ter oportunidade para gerar renda e transformar em riqueza para o país.

O Microempreendedor Individual (MEI) é uma importante ferramenta de desenvolvimento. Pode ser considerada, um instrumento de redução de desigualdade social, uma vez que é muito fácil acessar, e com alguns cliques gerar sua obrigação de pagar, e com um pouco mais de $\mathrm{R} \$ 50,00$ (cinquenta reis) mensais, está em dia com o fisco conseguindo empreender e permanecer no sistema.

É um sistema que está em constante alteração para tornar cada vez mais fácil o ingresso, e ampliar cada vez mais o número de pessoas que possam entrar na formalidade. O importante é que o sistema é exitoso e se torna importante fonte de renda, o que faz melhorar a economia do pais, consequentemente o estado de bem-estar da população, ao considerar o número de pessoas que foram incluídas socialmente e economicamente com a adesão ao programa do Microempreendedor Individual.

\section{REFERÊNCIAS BIBLIOGRÁFICAS}

ALMEIDA, Paulo Roberto de. A economia política das relações econômicas internacionais do Brasil: paradigmas e realidades, de Bretton Woods atualidade. II Encontro de Economia Política Internacional. Rio de Janeiro, 10 a 12 de maio de 2017. 
BERCOVICI, Gilberto; MASSONETTO, Luis Fernando. A constituição dirigente invertida: a blindagem da constituição financeira e a agonia da constituição econômica. Boletim de Ciências Econômicas XLIX. Coimbra. 2006.

BIER, Clerilei; AMORIM, Andreia Silva da Rosa. Sustentabilidade: Entre a prática e a estratégia empresarial para um novo padrão de desenvolvimento in Empresa, funcionalização do Direito e sustentabilidade: função sócio-solidária da empresa e desenvolvimento, v. 4. Editora Clássica. Curitiba. 2013.

BRASIL. Lei Complementar $n^{\circ} 123$, de 14 de dezembro de 2006. Estatuto Nacional da Microempresa e da Empresa de Pequeno Porte. Disponível em: < http://www.planalto.gov.br/ccivil_03/leis/lcp/lcp123.htm>. Acesso em 5 jan. 2019.

BRASIL. Lei Complementar. $\mathrm{n}^{\mathrm{o}}$ 128, de 19 de dezembro de 2008. Disponível em: < http://www.planalto.gov.br/ccivil_03/leis/lcp/lcp128.htm>. Acesso em: 6 jan. 2019.

CHOMSKY, Noam. O lucro ou as pessoas. Neoliberalismo e ordem global, v. 3, 2002.

CREDDO, Raquel de Naday Di. O pagamento de tributos e a justiça fiscal. Revista Jurídica da Procuradoria Geral do Estado do Paraná, Curitiba, n. 3, p. 189, 2012.

FORTES, Gabriel Barroso; POMPEU, Gina Marcilio. Os limites do estado na promoção do desenvolvimento: democracia, direitos humanos e globalização. Direito e Desenvolvimento, v. 7, n. 2, p. 57-76, 2016.

IFI, 2018. Instituto de Fiscal Independente. Senado Federal. Consulta feita em 17052020. Disponível em: <http://www2.senado.leg.br/bdsf/bitstream/handle/id/542807/RAF17_JUN2018_TopicoEspec ial_CargaTributaria.pdf $>$. Acesso em: 7 jan, 2019.

MEIRA JUNIOR, J.J, MACEI, D.N. Análise dos princípios constitucionais da ordem econômica e sua influência no direito brasileiro. Revista Eletrônica do Curso de Direito das Faculdades OPET. Curitiba. Ano IX. N 16, jan./jun., 2017.

NETO, Aristides Monteiro; CASTRO, César Nunes de; BRANDÃO, Carlos Antônio. Organizadores. Desenvolvimento regional no Brasil: políticas, estratégias e perspectivas. Rio de Janeiro: Ipea, 475 p. 2017.

NUNES, António José Avelãs. Neoliberalismo e direitos humanos. Editora: Renovar. 135 p. 2003.

NUSBAUM, Martha C. Fronteiras da Justiça: deficiência, Nacionalidade, Pertencimento à Espécie. Tradução de Susana de Castro. Editora: WMF Martins Fontes. São Paulo. 2013.

NUSBAUM, Martha C. Sem Fins Lucrativos: Por que a democracia precisa das humanidades. Tradução de Fernando Santos. Editora: WMF Martins Fontes. São Paulo. 2015.

OLIVEIRA, Carlos Alberto Alvaro de. O processo civil na perspectiva dos direitos fundamentais. In: Revista de Processo. 2004. 
PIMENTEL, José et al. 10 anos do Simples Nacional. Cadernos FGV Projetos. Ano 11. no 29. ISSN 19844883. Dezembro, 2016.

POMPEU, Gina Vidal Marcílio.; SIQUEIRA, Natercia Sampaio. Democracia Contemporânea e os critérios de Justiça para o Desenvolvimento Sócioeconômico: Direito constitucional nas relações econômicas. 1 ed. Editora Lumen Juris. Rio de Janeiro, 2017.

POMPEU, Gina Vidal; SIQUEIRA, Natércia Sampaio. Democracia contemporânea e os critérios de justiça para o desenvolvimento socioeconômico: direito constitucional nas relações econômicas. 1 ed. Rio de Janeiro: Lumen Juris, 2017.

RECEITA FEDERAL. Carga tributária no Brasil, 2018. Disponível em: $<$ http://receita.economia.gov.br/dados/receitadata/estudos-e-tributarios-e-aduaneiros/estudose-estatisticas/carga-tributaria-no-brasil/ctb-2018-publicacao-v5.pdf >. Acesso em: 17 mai. 2020.

RECEITA FEDERAL. Simples Nacional, 2020. Disponível em: $<$ http://www8.receita.fazenda.gov.br/SimplesNacional/Arrecadacao/Estatisticas Arrecadacao.a spx>. Acesso em: 17 mai. 2020.

RODAS, Sérgio. Simples Nacional só é vantajoso para $20 \%$ das empresas de serviços, diz análise. Boletim de Notícias Conjur. Cargas Tributárias. 2014 Disponível em: $<$ http://www.conjur.com.br/2014-dez-10/embargada-simples-nacional-vantajoso-20empresas-analise>. Acesso em: 28 de jun. 2017.

SANTOS, Cleônimo dos. Simples Nacional. 4.ed. São Paulo: Sage -IOB, 2016.

SCHOURI, Luís Eduardo; GALDINO, Guilherme. Tratamento favorecido a pequenas empresas: entre nacionalidade, livre concorrência e uniformidade. A ordem econômica constitucional/Fábio Nusdeo, coordenador. - São Paulo: Thomson Reuters Brasil,2019.

SCHUMPETER, J. A. Teoria do desenvolvimento econômico. 3ed. São Paulo: Nova Cultural, 1988.

SEBRAE. Perfil do Microempreendedor Individual 2013: Série Estudos e Pesquisas. Brasília: Sebrae. 2013.

YUNUS, Muhammad; WEBER, Karl. Um mundo sem pobreza: a empresa social e o futuro do capitalismo. Ática, 2008.

Data de Submissão: 24/05/2020

Data de Aceite: 09/09/2020 